\title{
Stool DNA Testing for Colorectal Cancer: Development and Advances
}

\author{
Steven H. Itzkowitz, M.D., FACP, FACG, AGAF
}

The Dr. Henry D. Janowitz Division of Gastroenterology, Mount Sinai School of Medicine, NY, USA

Screening for colorectal cancer is one of the most effective public health interventions. Although colonoscopy is the preferred method in many settings, colonoscopy can miss lesions, interval neoplasms can arise after a normal colonoscopy, and some patients refuse to undergo colonoscopy. In the last decade, detection of neoplasia-associated genetic alterations in the stool has become feasible. First-generation stool DNA tests demonstrated better sensitivity for colorectal cancer than fecal occult blood tests. Improvements to stool DNA tests have made them more sensitive and less complex. The newer marker panels can detect colorectal cancer and even the majority of advanced adenomas, regardless of location in the colon. This review summarizes the development and advances to stool DNA testing for colorectal cancer. (Intest Res 2012;10:134-141)

Key Words: Colorectal Neoplasms; Stool DNA Test; Screening; Adenoma

\section{INTRODUCTION}

Colorectal cancer (CRC) is a very common and often fatal cancer in the United States and worldwide. Screening has been shown to be highly effective in preventing the incidence and subsequent mortality from CRC. For this reason, in the United States, CRC screening has been endorsed by all major medical societies, ${ }^{1}$ receiving a Grade-A recommendation by the United States Preventive Services Task Force (USPSTF) in its most recent guidelines. ${ }^{2}$ Screening methods available to patients and physicians include structural screening tests that provide images of the colon by either endoscopic (colonoscopy, flexible sigmoidoscopy) or radiographic (air contrast barium enema, computed tomographic colonography) means, or by non-invasive stool-based tests. Over the last decade, colonoscopy has become a popu-

Received December 6, 2011. Revised December 12, 2011. Accepted December 15, 2011.

- Correspondence to : Steven H. Itzkowitz, M.D., FACP, FACG, AGAF, The Dr. Henry D. Janowitz Division of Gastroenterology, Mount Sinai School of Medicine, One Gustave Levy Place, New York 10029, USA Tel: +1-212-659-9697, Fax: +1-212-849-2574

E-mail: steven.itzkowitz@mountsinai.org

*The author receives research support and serves on the Scientific Advisory Board of Exact Sciences Corporation. lar, and in most cases the preferred, screening test in the United States because it not only detects cancers and polyps with high accuracy, but is simultaneously therapeutic because of its ability to remove polyps and early cancers.

Despite its strengths, colonoscopy is associated with organizational, logistical, and patient-related barriers that often limit its full acceptance and utilization as a screening method. These include the need for a bowel prep, the use of sedation in most centers (which also requires the need for a patient escort), loss of time from work, risk of complications such as perforation and bleeding, and the small but real chance that colonoscopy may miss polyps and even cancers. Patients sometimes express fear of the procedure and embarrassment.

For all these reasons, stool-based screening tests are an attractive alternative for many screen-eligible people because they do not require a cleansing bowel prep or the need to miss work, are non-invasive, and can be done in the privacy of the home. In parts of the world where colonoscopy resources are limited, stool-based tests, which to date have been based on detecting occult blood, remain the foundation of CRC screening. Indeed, for decades, stool-based tests relied on detecting fecal occult blood with the chemical guaiac reagent (gFOBT; for example, Hemoccult). Whereas this approach re- 
duces CRC mortality by one-third when the test is performed annually, ${ }^{3}$ gFOBTs, including the more sensitive versions (e.g., Hemoccult SENSA), have limited sensitivity and specificity for CRC, are not very good at detecting adenomas, and rely on patients complying with annual, if not, biennial testing to demonstrate efficacy. Newer stool tests include fecal immunochemical tests (FIT) and stool DNA tests. The performance of FIT tests for detecting colon cancer and adenomas has recently been reviewed. ${ }^{4}$ This review will summarize the current status of stool DNA testing for CRC screening.

\section{DEVELOPMENTAL ASPECTS}

What makes DNA such a highly relevant and promising analyte for detecting colorectal polyps and cancer in stool is that so much is known about the molecular pathogenesis of colorectal neoplasia. However, until 15 years ago, the notion that specific gene mutations could be detected among the enormous amount of bacterial DNA in stool seemed an insurmountable challenge. Indeed, it is estimated that human DNA represents only $0.01 \%$ of total stool DNA; the other $99.99 \%$ coming from non-human sources such as the microflora and diet. ${ }^{5}$ The use of sensitive polymerase chain reaction (PCR) techniques with PCR inhibitors, and modern approaches for capturing DNA, greatly facilitated the development of methods to detect mutated human DNA from stool and these methods continue to improve. At present, the latest tests are now limited more by the choice of marker(s), their method of analysis, and by the biology of the neoplasm, rather than by our ability to isolate DNA itself. Another advantage is that, unlike fecal occult blood tests, older versions of which required 2-3 stool samples for a single test, stool DNA testing requires only a single stool sample, which theoretically should improve patient acceptance.

The earliest stool DNA studies investigated individual markers as proof-of-principle that gene mutations such as KRAS and P53 could in fact be detected in stool (reviewed in Reference 5). These studies showed that the same mutation that occurred in cancer tissue could be found in the patient's stool with an approximate $80 \%$ concordance. However, concordance ranged from $53 \%$ to $100 \%$, and thus, the sensitivity for detecting CRC in these early single-marker stool DNA studies was usually less than $40 \%$.

This led to the development of multi-marker panels. These panels are now considered "first-generation" stool DNA tests (Table 1). ${ }^{5}$ These tests analyzed a rather complex marker panel of multiple mutations in genes known to be involved in microsatellite stable CRCs (APC, TP53, KRAS), a marker of microsatellite instability (BAT-26), and an assay that detected long DNA (a surrogate measure of aberrant apoptosis). To establish the approximate sensitivity and specificity of the test, preliminary studies utilized case-control designs to investigate patients with $\mathrm{CRC}$ versus those with normal colonoscopies. Several independent studies using the same multimarker panel (PreGen-Plus; Exact Sciences Corporation, Marlborough, MA, USA), demonstrated an approximate $62-69 \%$ sensitivity for CRC, with specificity of $97-98 \%$ (Table 1). The first study from the Mayo Clinic had the highest sensitivity (91\%), which in hindsight was likely due to the rapid freezing of the stool samples by the central laboratory shortly after evacuation. ${ }^{6}$ In most other studies, stool samples were chilled by having the patient place frozen packs around the sample container (or freezing the container with the sample), and shipping the specimen by overnight courier.

In the past several years, technical advances have emerged that have improved the test performance characteristics. Techniques have been developed to preserve stool DNA with a stabilizing buffer, ${ }^{7}$ and for better extraction of DNA from stool. ${ }^{8}$ In fact, these two improvements alone resulted in an increase in sensitivity for $\mathrm{CRC}$ of the PreGen-Plus assay from $52 \%$ to $73 \%$. ${ }^{9}$ In addition, highly sensitive techniques such as beads, emulsion, amplification, and magnetics (BEAMing), ${ }^{11}$ digital melt curve analysis (DMC), ${ }^{12}$ and quantitative allele-specific real-time target and signal amplification $(\text { QuARTS) })^{13}$ can increase the ability to detect very lowabundance mutations in stool. For example, in a recent pilot study of 26 adenomas with tissue-proven KRAS mutations, the DMC assay detected $59 \%$ of adenomas, which was superior to Hemoccult (7\%), Hemoccult SENSA (15\%), and PreGen-Plus (26\%), without compromising specificity. ${ }^{12,14}$ 


\section{PERFORMANCE OF STOOL DNA TESTS IN SCREENING TRIALS}

Building upon the promising results of the preliminary series using first generation stool DNA tests, two large prospective multicenter studies of asymptomatic, average-risk individuals were performed (Table 1). The first study by Imperiale and colleagues compared stool DNA (PreGen-Plus) to Hemoccult II. Hemoccult II was chosen as the comparator because it was the accepted standard stool-based screening test at the time. All subjects in the trial underwent colonoscopy as the gold standard. ${ }^{9}$ The results revealed that the sensitivity for detecting CRC was $52 \%$ for stool DNA, compared to $13 \%$ for Hemoccult II. The two tests had comparable (94-95\%) specificity. The sensitivity of stool DNA for adenomas with high-grade dysplasia and for villous adenomas was $33 \%$ and $18 \%$, respectively; double the sensitivity rates with Hemoccult II. This study firmly established that in an average-risk screening population, stool DNA was better than gFOBT for detecting CRC. However, the sensitivity of $52 \%$ for CRC was lower than expected, which was mainly due to poor performance of the long DNA component of the assay due to DNA degradation in transit. As mentioned above, techniques are now available for better DNA preservation and extraction, and these are now employed in newer versions of the stool DNA test (see below).

A second large-scale prospective average-risk study was performed by Ahlquist et al. ${ }^{15}$ during the years 2001-2007. Initially, the same PreGen-Plus assay of the Imperiale study was used (referred to in the study as "Stool DNA Test-1"; SDT-1). However, during the study, the manufacturer altered the stool DNA test, prompting an unplanned interim analysis. The newer Stool DNA Test-2 (SDT-2) was applied to all patients in the study who had CRC, high-grade dysplasia, adenomas larger than $2 \mathrm{~cm}$, and a sample of 50 subjects with adenomas between $1-2 \mathrm{~cm}$ and 75 subjects with normal colonoscopy. The SDT-2 assay consisted of three markers considered to be more broadly informative of adenomas as well as cancers ${ }^{16}$ : KRAS mutations; vimentin gene methylation, and scanning of the $A P C$ mutation cluster region. All stool DNA tests were compared to Hemoccult as well as the more sensitive
Hemoccult SENSA test, and again, all patients underwent colonoscopy. For detecting screen-relevant neoplasms (SRN; defined as CRC, high-grade dysplasia or adenomas at least $1 \mathrm{~cm}$ in size), PreGen-Plus had a sensitivity of $20 \%$, which was better than Hemoccult (11\%) but similar to Hemoccult SENSA (21\%). However, the sensitivity of SDT-2 for SRN was better (46\%), and compared more favorably to that of Hemoccult (16\%) and Hemoccult SENSA (24\%). SDT-2 detected substantially more adenomas $1 \mathrm{~cm}$ or larger than either of the two FOBTs.

The data from these stool DNA trials, and the preliminary studies leading up to them, formed the basis for including stool DNA among CRC screening options by the American Cancer Society, the US Multi-Society Task Force (USMSTF), and the American College of Radiology, ${ }^{1}$ and the American College of Gastroenterology, ${ }^{17}$ thereby acknowledging the potential for stool DNA screening tests. However, the USPSTF found that there was insufficient evidence to recommend fecal DNA testing for routine screening. ${ }^{2}$ This is because first-generation stool DNA tests, despite their superiority over guaiac tests, still demonstrated modest sensitivity for cancer (in the 55\% range), were complex assays (thereby making them expensive), and were not very good at detecting adenomas. It is important to realize, however, that the original molecular markers were purposely chosen to detect cancers more than adenomas.

\section{IMPROVEMENTS TO STOOL DNA TESTS}

In the past several years it has become increasingly apparent that hypermethylation of the promoter region of genes is a more common pathway in CRC pathogenesis than previously thought. One of the earliest observations came from Chen et al. ${ }^{18}$ who made the intriguing observation that hypermethylation of the vimentin gene, a gene not considered to be part of the usual molecular alterations associated with the adenoma-carcinoma sequence, was only rarely found in normal colonic tissue, but was quite common in colonic adenoma and carcinoma tissues. When analyzed in stool, vimentin methylation was present in $43 \%$ of patients with CRC but only $10 \%$ of normal controls (Table 1). This prompted other stool DNA studies analyzing vi- 
mentin methylation as well as long DNA. Using improved methods of DNA preservation and purification from stool, Itzkowitz et al. ${ }^{10}$ reported that vimentin methylation as a single marker, resulted in $73 \%$ sensitivity for CRC, with $87 \%$ specificity. A simpler version of the long DNA assay that analyzed two instead of four DNA loci, resulted in sensitivity and specificity of $65 \%$ and $93 \%$, respectively. The combination of the two markers gave optimal sensitivity $(88 \%)$ and specificity (82\%). Importantly, cancers were detected regardless of location in the colon or stage. Nearly identical findings were observed in an independent validation set of patients. ${ }^{19}$ What emerged from these studies, which to date enrolled the most number of subjects with cancer and normals of all the most recent stool DNA studies, was the observation that a single methylation marker: 1) can have greater than $75 \%$ sensitivity for CRC 2) can detect cancer of the proximal colon just as well as the distal colon; 3) can identify CRC regardless of stage; 4) can make stool DNA testing easier to perform because of fewer markers, thereby enabling distribution to local clinical laboratories.

Following suit, many other pilot studies in the last few years have looked at other methylated genes as markers of CRC and adenomas in stool. One of the most commonly studied genes is secreted frizzled-related protein $(S F R P) 2$, a gene involved in inhibiting the wnt signaling pathway. Epigenetic silencing of SFRP2 by methylation is quite frequently found in the stool of patients with CRC, with sensitivities ranging from 63-94\% and specificity ranging from $77-96 \%$ in several small series (Table 1). The frequency of SFRP2 methylation is lower in stool DNA of adenoma patients, but seems to occur in approximately half of them (Table 1). A related gene, SFRP1 was found to be methylated in $84 \%$ of CRC compared to $14 \%$ of normals. ${ }^{20}$ Other promising methylated gene targets for stool DNA testing include tissue factor pathway inhibitor 2 (TFPI2), a potential tumor suppressor gene. This gene was aberrantly methylated in the tissue of almost all colorectal adenomas $(97 \%)$ and cancers $(99 \%){ }^{21}$ When analyzed in the stool of patients with stage I-III CRC and controls with normal colonoscopy, results of training and validation sets revealed that TFPI2 methylation demonstrated sensitivities ranging from $76-89 \%$ for cancer, $21 \%$ for ad- enomas, with specificity of approximately $93 \%$. Methylation of the promoter region of another tumor suppressor gene, N-myc downstream-regulated gene 4 (NDRG4), occurred in $70-86 \%$ of CRC tissues compared with $4 \%$ in non-cancerous colonic mucosa. ${ }^{22}$ In stool DNA, methylated NDRG4 had a sensitivity of $61 \%$ and $53 \%$ for detecting CRC in training and validation sets, respectively, with corresponding specificities of $93 \%$ and $100 \%$.

A very recent study by Ahlquist et al. ${ }^{13}$ analyzed a panel of methylated genes (vimentin, bone morphogenetic protein 3, NDGR4, and TFPI2), as well as mutant Kras and quantitative hemoglobin using the highly sensitive QuARTS technique. At a specificity of $89 \%$, this new panel demonstrated a sensitivity of $85 \%$ for CRC, and $63 \%$ for adenomas over $1 \mathrm{~cm}$. Colon cancers were positive regardless of stage and location, and positivity rates increased with increasing size of adenomas (reaching $92 \%$ for those larger than $4 \mathrm{~cm}$ ). Similar findings were reported in a smaller series from these authors in which stool DNA was compared to plasma methylated Septin 9 levels, with the finding that the stool DNA test was superior. ${ }^{23}$

As shown in Table 1, the sensitivity for detecting adenomas with many of the newer markers is generally in the $45-65 \%$ range. Larger studies of patients with adenomas will be required before the value of any given marker or set of markers can be established.

\section{COST-EFFECTIVENESS}

An earlier cost-effectiveness analysis placed stool DNA testing in context with gFOBT, sigmoidoscopy and colonoscopy, and modeled the stool DNA cost at $\$ 695 .^{24}$ This analysis revealed that stool DNA testing every 5 years would result in $\$ 47,700 /$ life year gained, and that in order to make stool DNA comparable to colonoscopy, it would have to achieve sensitivity of $65 \%$ for CRC, $40 \%$ for large adenomas, $95 \%$ specificity, a screening interval of 2 years, and a cost of $\$ 195$. The same authors recently updated their cost-effectiveness analysis, this time including FIT, which was modeled to have sensitivity for CRC of $76 \%, 40 \%$ for large adenoma, specificity of $91 \%$ and cost of $\$ 22 .{ }^{25}$ Newer versions of the stool DNA test were modeled at a cost of 
$\$ 300$ and a base case interval of every 3 years. In this analysis, FIT dominated over colonoscopy and all versions of stool DNA test, assuming perfect adherence. However, stool DNA testing with complete adherence became more effective than FIT if the adherence with FIT testing fell below $50 \%$, and assuming a per-cycle adherence of $50 \%$ for stool DNA test, it was more effective than FIT if adherence with FIT dropped below $19 \%$. Needless to say, adherence with stool testing is a crucial factor contributing to the success of a screening program. ${ }^{26}$ Just how much impact the frequency of a stool test (e.g., annual vs. every 3-5 years), or the number of stools per cycle, will have on patient adherence remains to be studied. However, some of the newer stool DNA tests demonstrate much better sensitivity for CRC and adenomas, with very reasonable specificity, using only a few markers. This suggests that improved stool DNA tests may indeed be at least as cost-effective as other stool-based tests that are based on detecting occult blood.

\section{PATIENT ACCEPTANCE}

A prospective survey of 4,042 (84\%) subjects participating in the Imperiale study, whereby all subjects performed stool DNA test, Hemoccult II, and colonoscopy, revealed that stool DNA testing received the same or higher mean ratings than gFOBT for most prep- and test-related features, and except for perceived accuracy, also received higher ratings than colonoscopy. ${ }^{27}$ Thus, a higher proportion of patients preferred stool DNA $(45 \%)$ to both FOBT (42\%) and colonoscopy $(15 \%)$. A more recent study by the same group administered a computerized decision aid to ambulatory care patients in a primary care setting who had not previously undergone CRC screening (or only FOBT testing). ${ }^{28}$ Theoretically, colonoscopy (51\%), stool DNA (28\%) and FOBT $(18 \%)$ were preferred over other screening options. The findings suggested that there are two groups of patients: those who prefer the most accurate test (colonoscopy) and those who prefer the least invasive test (stool DNA and FOBT). More work is needed to explore preferences for stool DNA compared to FIT, especially using more recent estimates of sensitivity, specificity, and costs.

\section{EMERGING APPLICATIONS OF STOOL DNA TESTS}

Although not yet tested in a clinical trial, it has been suggested that stool DNA testing be considered during the interval between colonoscopies in an effort to detect neoplasms, particularly those in the proximal colon, that are sometimes missed by colonoscopy. ${ }^{29}$ Also, since stool may contain DNA from any organ that communicates with the luminal gastrointestinal (GI) tract, it is conceivable that stool DNA testing might be useful for detecting upper GI neoplasms. Nagasaka et al. ${ }^{30}$ recently reported that $S F R P 2$ and ras association domain family member 2 (RASSF 2) methylation can detect gastric as well as CRC in stool DNA. Kisiel et al. ${ }^{31}$ reported that the combination of methylated BMP3 and mutant Kras in stool had $67 \%$ sensitivity for pancreatic cancer at $90 \%$ specificity. Ahlquist et al. ${ }^{14}$ have also reported that fecal DNA can be used to detect not only cancers of the colorectum and stomach, but also those of the oropharynx, esophagus, pancreas, and bile duct and/or gallbladder. Collectively, these cancers result in over 130,000 deaths each year in the US alone. Since some of these cancers (e.g., pancreatic and biliary cancer) are hard to screen with current imaging techniques, further development of stool DNA as a pan-detection assay for gastrointestinal tract cancers represents an intriguing possibility.

\section{UNANSWERED QUESTIONS}

Despite the advances in stool DNA technology and the incorporation of stool DNA testing in at least some screening guidelines, several questions remain. At the present time, stool DNA tests are not meant to replace colonoscopy, but rather, to be used as a complementary test. Some issues that will require further investigation include:

1) What advice should be given to a patient who has a positive stool DNA test but a normal colonoscopy?

2) How well will the newer tests detect adenomas or serrated polyps?

3) How will stool DNA testing be integrated into overall colon cancer screening efforts? (For example, should stool DNA tests be used as an interval test be- 
Table 1. Summary of Stool DNA Studies

\begin{tabular}{|c|c|c|c|c|}
\hline \multirow{2}{*}{ First author, year (Ref) } & \multirow{2}{*}{ Marker panel } & \multicolumn{2}{|c|}{ Sensitivity } & \multirow{2}{*}{$\begin{array}{c}\text { Specificity } \\
\text { negative/normal }\end{array}$} \\
\hline & & Cancer & Adenomas & \\
\hline & & \multicolumn{2}{|c|}{ First Generation Stool DNA Tests } & \\
\hline Dong et al., $2001^{32}$ & P53; KRAS; MSI & $36 / 51(71)$ & -- & -- \\
\hline Rengucci et al., $2001^{33}$ & P53; KRAS; MSI & $31 / 46(67)$ & -- & $18 / 18(100)$ \\
\hline Koshiji et al., $2002^{34}$ & $\mathrm{LOH} ; \mathrm{MSI}$ & $29 / 30(97)$ & -- & $30 / 30(100)$ \\
\hline Ahlquist et al., $2000^{6}$ & Pre-Gen Plus* & 20/22 (91) & 9/11 (82) & 26/28 (93) \\
\hline Tagore et al., $2003^{35}$ & Pre-Gen Plus & $33 / 52(63)$ & $16 / 28(57)$ & 111/113 (98.2) \\
\hline $\begin{array}{l}\text { Syngal et al., } 2002^{36} ; \\
2003^{37}\end{array}$ & Pre-Gen Plus & 40/65 (62) & 6/22 (27) & -- \\
\hline Brand et al., $2002^{38}$ & Pre-Gen Plus & $11 / 16(69)$ & -- & -- \\
\hline Calistri et al., $2003^{39}$ & Pre-Gen Plus & $33 / 53(62)$ & -- & $37 / 38(97)$ \\
\hline \multicolumn{2}{|l|}{ Average risk subjects: } & & & \\
\hline Imperiale et al., $2004^{9}$ & Pre-Gen Plus & $16 / 31(51.6)$ & 84/689 (12) & $1,344 / 1,423(94.4)$ \\
\hline \multirow[t]{3}{*}{ Ahlquist et al., $2008^{15}$} & Pre-Gen Plus & $3 / 12(25)$ & $47 / 614(7.7)$ & 2,246/2,340 (96) \\
\hline & $\mathrm{SDT}-2^{\dagger}$ & $11 / 19(58)$ & $55 / 123(45)$ & $63 / 75(84)$ \\
\hline & & \multicolumn{2}{|c|}{ Newer Stool DNA Tests } & \\
\hline Lenhard et al., $2005^{40}$ & HIC1 methylation & $11 / 26(42)$ & $4 / 13(31)$ & $32 / 32(100)$ \\
\hline Petko et al., $2005^{41}$ & CDKN2A; MGMT; MLH1 methyl. & -- & $16 / 29(55)$ & $7 / 19(37)$ \\
\hline Chen et al., $2005^{18}$ & Vimentin methylation & $43 / 94(46)$ & -- & 178/198 (90) \\
\hline $\begin{array}{l}\text { Itzkowitz et al., } 2007^{10}, \\
2008^{19}\end{array}$ & Pre-Gen Plus Version $2^{\ddagger}$ & $68 / 82(83)$ & 6/7 (86) & 298/363 (82) \\
\hline \multirow[t]{2}{*}{ Müller et al., $2004^{42}$} & SFRP2 methylation (test set) & 9/10 (90) & -- & $3 / 13(77)$ \\
\hline & SFRP2 methylation (validation) & $10 / 13(77)$ & -- & $3 / 13(77)$ \\
\hline Huang et al., $2007^{43}$ & SFRP2 methylation & 49/52 (94) & $11 / 21(52)$ & 23/24 (96) \\
\hline Huang et al., $2007^{44}$ & SFRP2; HPP1; MGMT meth. & $50 / 52(96)$ & $15 / 21(71)$ & 23/24 (96) \\
\hline \multirow[t]{2}{*}{ Leung et al., $2007^{45}$} & SFRP2 methylation & $6 / 20(30)$ & $3 / 25(12)$ & $26 / 30(87)$ \\
\hline & Any of 6 methylated genes & $15 / 20(75)$ & $17 / 25(68)$ & $27 / 30(90)$ \\
\hline Wang and Tang, $2008^{46}$ & SFRP2 methylation & $60 / 69(87)$ & $21 / 34(62)$ & 28/30 (93) \\
\hline Oberwalder et al., $2008^{47}$ & SFRP2 methylation & -- & $6 / 13(46)$ & $6 / 6(100)$ \\
\hline Tang et al., $2011^{48}$ & SFRP2 methylation & 142/169 (84) & $29 / 63(46)$ & 28/30 (93) \\
\hline \multirow[t]{3}{*}{ Nagasaka et al., $2009^{30}$} & SFRP2 methylation & $53 / 84(63)$ & $18 / 56(32)$ & $103 / 113(91)$ \\
\hline & RASSF2 methylation & $38 / 84(45)$ & $7 / 56(13)$ & $107 / 113(95)$ \\
\hline & SFRP2 or RASSF2 methylation & 63/84 (75) & $25 / 56(44)$ & 101/113 (89) \\
\hline Zhang et al., $2007^{20}$ & SFRP1 methylation & $16 / 19(84)$ & 7/7 (100) & 12/14 (86) \\
\hline Glöckner et al., $2009^{21}$ & TFPI2 methylation & $36 / 47(76)$ & $4 / 19(21)$ & (79-93) \\
\hline \multirow[t]{3}{*}{ Zhang et al., $2012^{49}$} & TFPI2 methylation & $41 / 60(68)$ & 7/20 (35) & $30 / 30(100)$ \\
\hline & Long DNA & $52 / 60(87)$ & $5 / 20(25)$ & 25/30 (83) \\
\hline & Both & $52 / 60(87)$ & $11 / 20(55)$ & 25/30 (83) \\
\hline \multirow[t]{2}{*}{ Melotte et al., $2009^{22}$} & NDRG4 methylation (test set) & $17 / 28(61)$ & -- & $42 / 45$ (93) \\
\hline & NDRG4 methylation (validation) & $25 / 47(53)$ & -- & $30 / 30(100)$ \\
\hline Baek et al., $2009^{50}$ & Vimentin; MGMT; MLH1 meth. & $45 / 60(75)$ & $31 / 52(60)$ & 32/37 (87) \\
\hline Mayor et al., $2009^{51}$ & Chromosome 2q14.2 meth. & $8 / 30(27)$ & -- & $29 / 30(97)$ \\
\hline Ahlquist et al., $2012^{13}$ & $\begin{array}{l}\text { Methylated (vimentin, BMP3, NDGR4, } \\
\text { TFPI2) mutant Kras; quantitative } \\
\text { hemoglobin }\end{array}$ & $214 / 252(85)$ & $\begin{array}{c}\text { 84/133 (63) } \\
\text { (adenomas >1 cm) }\end{array}$ & $261 / 293$ (89) \\
\hline
\end{tabular}

*PreGen-Plus marker panel: APC; KRAS; P53 MSI; long DNA

${ }^{\dagger}$ SDT2: KRAS; APC scan; methylated vimentin

${ }^{\ddagger}$ PreGen-Plus Version 2: methylated vimentin; long DNA

Values are presented as $\mathrm{n}(\%)$.

$\mathrm{LOH}$, loss of heterozygosity; MSI, microsatellite instability; HIC1, hypermethylated in cancer 1; CDKN2a, cyclin-dependent kinase inhibitor 2a; MGMT, O(6)-methylguanine-DNA methyltransferase; MLH1, mutL homologue 1; NDRG4, N-myc downstreamregulated gene 4. 
tween colonoscopies?)

4) What is an appropriate interval for stool DNA testing?

5) Will stool DNA testing be cost-effective?

6) Could stool DNA tests be developed for high-risk patients (e.g., Lynch Syndrome, inflammatory bowel disease) where colonoscopy intervals are very short and lesions can be missed at colonoscopy?

\section{CONCLUSION}

Stool DNA testing has better sensitivity for CRC than gFOBT, with comparable specificity in large-scale prospective studies of average-risk patients. Stool DNA testing, interval uncertain, has been endorsed in the most recent guidelines of the USMSTF but not the USPSTF. ${ }^{1,2}$ Advances in technology, including the use of newer and simpler marker panels, many of which are hypermethylated genes, have demonstrated much higher sensitivities than first generation tests, albeit with some compromise in specificity. This has resulted in reduced test costs. Studies suggest that patient preference is high for stool DNA testing. Advances in analytical methods and the identification of new molecular markers of CRC should make stool DNA testing more sensitive and specific. Stool DNA tests remain suboptimal for detecting adenomas, but this is improving. It is expected that stool DNA testing will become a very reasonable screening option in the near future.

\section{REFERENCES}

1. Levin B, Lieberman DA, McFarland B, et al; American Cancer Society Colorectal Cancer Advisory Group; US Multi-Society Task Force; American College of Radiology Colon Cancer Committee. Screening and surveillance for the early detection of colorectal cancer and adenomatous polyps, 2008: a joint guideline from the American Cancer Society, the US MultiSociety Task Force on Colorectal Cancer, and the American College of Radiology. CA Cancer J Clin 2008;58:130-160.

2. Whitlock EP, Lin JS, Liles E, Beil TL, Fu R. Screening for colorectal cancer: a targeted, updated systematic review for the U.S. Preventive Services Task Force. Ann Intern Med 2008; 149:638-658

3. Hewitson P, Glasziou P, Watson E, Towler B, Irwig L. Cochrane systematic review of colorectal cancer screening using the fecal occult blood test (hemoccult): an update. Am J Gastroenterol 2008;103:1541-1549.
4. Potack J, Itzkowitz SH. Practical advances in stool screening for colorectal cancer. J Natl Compr Canc Netw 2010;8:81-92.

5. Osborn NK, Ahlquist DA. Stool screening for colorectal cancer: molecular approaches. Gastroenterology 2005;128:192-206.

6. Ahlquist DA, Skoletsky JE, Boynton KA, et al. Colorectal cancer screening by detection of altered human DNA in stool: feasibility of a multitarget assay panel. Gastroenterology 2000; 119:1219-1227.

7. Olson J, Whitney DH, Durkee K, Shuber AP. DNA stabilization is critical for maximizing performance of fecal DNA-based colorectal cancer tests. Diagn Mol Pathol 2005;14:183-191.

8. Whitney D, Skoletsky J, Moore K, et al. Enhanced retrieval of DNA from human fecal samples results in improved performance of colorectal cancer screening test. J Mol Diagn 2004;6:386-395.

9. Imperiale TF, Ransohoff DF, Itzkowitz SH, Turnbull BA, Ross ME; Colorectal Cancer Study Group. Fecal DNA versus fecal occult blood for colorectal-cancer screening in an average-risk population. N Engl J Med 2004;351:2704-2714.

10. Itzkowitz SH, Jandorf L, Brand R, et al. Improved fecal DNA test for colorectal cancer screening. Clin Gastroenterol Hepatol 2007;5:111-117.

11. Diehl F, Schmidt K, Durkee KH, et al. Analysis of mutations in DNA isolated from plasma and stool of colorectal cancer patients. Gastroenterology 2008;135:489-498.

12. Zou H, Taylor WR, Harrington JJ, et al. High detection rates of colorectal neoplasia by stool DNA testing with a novel digital melt curve assay. Gastroenterology 2009;136:459-470.

13. Ahlquist DA, Zou H, Domanico M, et al. Next-generation stool DNA test accurately detects colorectal cancer and large adenomas. Gastroenterology 2012;142:248-256.

14. Ahlquist DA. Next-generation stool DNA testing: expanding the scope. Gastroenterology 2009;136:2068-2073.

15. Ahlquist DA, Sargent DJ, Loprinzi CL, et al. Stool DNA and occult blood testing for screen detection of colorectal neoplasia. Ann Intern Med 2008;149:441-450.

16. Kann L, Han J, Ahlquist D, et al. Improved marker combination for detection of de novo genetic variation and aberrant DNA in colorectal neoplasia. Clin Chem 2006;52:2299-2302.

17. Rex DK, Johnson DA, Anderson JC, Schoenfeld PS, Burke CA, Inadomi JM; American College of Gastroenterology. American College of Gastroenterology guidelines for colorectal cancer screening 2009 [corrected]. Am J Gastroenterol 2009;104:739-750.

18. Chen WD, Han ZJ, Skoletsky J, et al. Detection in fecal DNA of colon cancer-specific methylation of the nonexpressed vimentin gene. J Natl Cancer Inst 2005;97:1124-1132.

19. Itzkowitz S, Brand R, Jandorf L, et al. A simplified, noninvasive stool DNA test for colorectal cancer detection. Am J Gastroenterol 2008;103:2862-2870.

20. Zhang W, Bauer M, Croner RS, et al. DNA stool test for colorectal cancer: hypermethylation of the secreted frizzledrelated protein-1 gene. Dis Colon Rectum 2007;50:1618-1626.

21. Glöckner SC, Dhir M, Yi JM, et al. Methylation of TFPI2 in stool DNA: a potential novel biomarker for the detection of colorectal cancer. Cancer Res 2009;69:4691-4699.

22. Melotte V, Lentjes MH, van den Bosch SM, et al. N-Myc downstream-regulated gene 4 (NDRG4): a candidate tumor suppressor gene and potential biomarker for colorectal cancer. J 
Natl Cancer Inst 2009;101:916-927.

23. Ahlquist DA, Taylor WR, Mahoney DW, et al. The stool DNA test is more accurate than the plasma septin 9 test in detecting colorectal neoplasia. Clin Gastroenterol Hepatol 2012;10:272277.

24. Song K, Fendrick AM, Ladabaum U. Fecal DNA testing compared with conventional colorectal cancer screening methods: a decision analysis. Gastroenterology 2004;126:1270-1279.

25. Parekh M, Fendrick AM, Ladabaum U. As tests evolve and costs of cancer care rise: reappraising stool-based screening for colorectal neoplasia. Aliment Pharmacol Ther 2008;27:697-712.

26. Zauber AG, Lansdorp-Vogelaar I, Knudsen AB, Wilschut J, van Ballegooijen M, Kuntz KM. Evaluating test strategies for colorectal cancer screening: a decision analysis for the U.S. Preventive Services Task Force. Ann Intern Med 2008;149:659669.

27. Schroy PC 3rd, Heeren TC. Patient perceptions of stool-based DNA testing for colorectal cancer screening. Am J Prev Med 2005;28:208-214

28. Schroy PC 3rd, Lal S, Glick JT, Robinson PA, Zamor P, Heeren TC. Patient preferences for colorectal cancer screening: how does stool DNA testing fare? Am J Manag Care 2007;13:393400 .

29. Markowitz SD, Itzkowitz SH, Berger BM. The effectiveness of colonoscopy in reducing mortality from colorectal cancer. Ann Intern Med 2009;150:816-817.

30. Nagasaka T, Tanaka N, Cullings HM, et al. Analysis of fecal DNA methylation to detect gastrointestinal neoplasia. J Natl Cancer Inst 2009;101:1244-1258.

31. Kisiel JB, Yab TC, Taylor WR, et al. Stool DNA testing for the detection of pancreatic cancer: Assessment of methylation marker candidates. Cancer 2011.

32. Dong SM, Traverso G, Johnson C, et al. Detecting colorectal cancer in stool with the use of multiple genetic targets. J Natl Cancer Inst 2001;93:858-865.

33. Rengucci C, Maiolo P, Saragoni L, Zoli W, Amadori D, Calistri D. Multiple detection of genetic alterations in tumors and stool. Clin Cancer Res 2001;7:590-593.

34. Koshiji M, Yonekura Y, Saito T, Yoshioka K. Microsatellite analysis of fecal DNA for colorectal cancer detection. J Surg Oncol 2002;80:34-40.

35. Tagore KS, Lawson MJ, Yucaitis JA, et al. Sensitivity and specificity of a stool DNA multitarget assay panel for the detection of advanced colorectal neoplasia. Clin Colorectal Cancer 2003;3:47-53.

36. Syngal S, Chung D, Willet C, Schoetz D. Stool DNA analysis for the detection and follow-up of colorectal cancer (CRC) and advanced adenomas (AA): sensitivity in a prospective series. Gastroenterology 2002;97(Suppl 1):332.

37. Syngal S, Chung D, Willet $C$, et al. The loss of stool DNA mutation abnormalities in colorectal neoplasia after treatment.
Gastroenterology 2003;124(Suppl 1):5.

38. Brand R, Shuber A, Laken S, Young C. Reliability of stool DNA mutation specific assay for colorectal cancer. Gastroenterology 2002;122(Suppl 1):479.

39. Calistri D, Rengucci C, Bocchini R, Saragoni L, Zoli W, Amadori D. Fecal multiple molecular tests to detect colorectal cancer in stool. Clin Gastroenterol Hepatol 2003;1:377-383.

40. Lenhard K, Bommer GT, Asutay S, et al. Analysis of promoter methylation in stool: a novel method for the detection of colorectal cancer. Clin Gastroenterol Hepatol 2005;3:142-149.

41. Petko Z, Ghiassi M, Shuber A, et al. Aberrantly methylated CDKN2A, MGMT, and MLH1 in colon polyps and in fecal DNA from patients with colorectal polyps. Clin Cancer Res 2005;11:1203-1209.

42. Müller HM, Oberwalder M, Fiegl H, et al. Methylation changes in faecal DNA: a marker for colorectal cancer screening? Lancet 2004;363:1283-1285.

43. Huang Z, Li L, Wang J. Hypermethylation of SFRP2 as a potential marker for stool-based detection of colorectal cancer and precancerous lesions. Dig Dis Sci 2007;52:2287-2291.

44. Huang ZH, Li LH, Yang F, Wang JF. Detection of aberrant methylation in fecal DNA as a molecular screening tool for colorectal cancer and precancerous lesions. World J Gastroenterol 2007;13:950-954.

45. Leung WK, To KF, Man EP, et al. Detection of hypermethylated DNA or cyclooxygenase-2 messenger RNA in fecal samples of patients with colorectal cancer or polyps. Am J Gastroenterol 2007; 102:1070-1076.

46. Wang DR, Tang D. Hypermethylated SFRP2 gene in fecal DNA is a high potential biomarker for colorectal cancer noninvasive screening. World J Gastroenterol 2008;14:524-531.

47. Oberwalder M, Zitt M, Wöntner C, et al. SFRP2 methylation in fecal DNA--a marker for colorectal polyps. Int J Colorectal Dis 2008;23:15-19.

48. Tang D, Liu J, Wang DR, Yu HF, Li YK, Zhang JQ. Diagnostic and prognostic value of the methylation status of secreted frizzled-related protein 2 in colorectal cancer. Clin Invest Med 2011;34:E88-95.

49. Zhang J, Yang S, Xie Y, et al. Detection of methylated tissue factor pathway inhibitor 2 and human long DNA in fecal samples of patients with colorectal cancer in China. Cancer Epidemiol 2012;36:73-77.

50. Baek YH, Chang E, Kim YJ, Kim BK, Sohn JH, Park DI. Stool methylation-specific polymerase chain reaction assay for the detection of colorectal neoplasia in Korean patients. Dis Colon Rectum 2009;52:1452-1459.

51. Mayor R, Casadomé L, Azuara D, et al. Long-range epigenetic silencing at 2q14.2 affects most human colorectal cancers and may have application as a non-invasive biomarker of disease. Br J Cancer 2009;100:1534-1539. 